\title{
A REVIEW OF PLATFORM CORPORATE GOVERNANCE IN THE DIGITAL ECONOMY AGE
}

\author{
Jianxin $\mathbf{G e}^{1}$ \\ Cong $\mathbf{L i}^{2}$
}

DOI: https://doi.org/10.31410/LIMEN.2020.151

\begin{abstract}
The development of the digital economy has given rise to a new industry structure. Many platform corporates (such as Facebook, Amazon, Uber and Alibaba) have emerged around the world with rapid development, strong momentum and service innovation. With the help of Internet digital technology, platform corporates promote the commonality and integration of resources and value co-creation among the subjects connected by the platform. At the same time, the operation of the platform has also caused hot issues such as "data disputes among platforms", "the responsibility boundary of platform corporates is difficult to determine" and "the platform mode challenges the traditional anti-monopoly restrictions". Therefore, it is very important to promote the research on platform corporate governance. This paper systematically reviews the important literature on platform governance in the Web of Science database. Firstly, it states the connotation of platform corporate and platform governance. Then, it expounds on the main viewpoints of platform enterprise governance from three aspects: governance body, governance system and governance mechanism. Finally, it analyzes and summarizes the characteristics of platform corporate governance, which are multiple subjectivities, the openness of boundary, dynamic relationship and ambiguity of rights and responsibilities, points out the existing problems of platform corporate governance, and provides guidance for the practice of platform corporate governance in the future.
\end{abstract}

Keywords: Digital economy, Platform corporate, Platform governance, Decentralization governance.

\section{INTRODUCTION}

$\mathrm{A}$ s mobile Internet, cloud computing, big data, a new generation of information technology such as artificial intelligence technology rapid development and economic digital levels rising, the new type of economic form of "digital economy" into people's horizons, become a leading science and technology revolution and industrial revolution, promote the important engine of economic development (Kenney \& Zysman, 2016; Adamik \& Nowicki, 2018; Lee, Malerba, \& Primi,2020), and even become a new trend in the global transition from the industrial economy to the digital economy (Kovacs, 2018), as well as a core force influencing the global competitive landscape (Liang Zheng\& Li Rui, 2020). Early scholars did not give a clear explanation of the concept of the digital economy, which can be traced back to its multifaceted, dynamic and transformative power of digital technology (Kannan \& Kopalle, 2001; Kim, Barua, \& Whinston, 2002; Hanseth \& Lyytinen, 2010; Makridakis, 2017). In 2016, in the G20 digital economy development and cooperation initiative, the digital economy is defined as, "to use digital as a key factor of knowledge and information, with modern information network as the important carrier, with the effective use 
of information communication technology as an important driver of efficiency improvement and optimization of the economic structure of a series of economic activities".

The development of the digital economy has spawned a new industry structure (Yoo, Henfridsson, \& Lyytinen, 2010; Ayres\& Williams,2004). Driven by the market trend, a large number of platform corporates with rapid development, strong momentum and service innovation have mushroomed in the international market (De Reuver, Sorensen,\& Basole,2018; Lehdonvirta et al., 2019), such as Facebook, Amazon, Uber, Alibaba, Tencent, etc., have subverted and reshaped the industrial chain supported by digital technology tools and systems including online communities, social media, e-commerce, and travel sharing (Sui\& Rejeski, 2002; Basole \& Karla, 2011; Constantinides, 2018; Akbar\& Tracogna, 2018). With the aid of digital technology, platform corporates promote the commonality and integration of resources and the interaction between platform connecting entities (Benlian Hilkert, \& Hess, 2015). To a certain extent, it improves the information asymmetry in the economic system, makes the supply and demand information of production and service more refined, and resources and information flow and cycle among the main bodies of the platform through the value network connected by the platform, so as to realize the value co-creation (Sambamurthy, Bharadwaj, \& Grover, 2003; Gawer, 2014). The rapid development of platform corporates has brought great changes to production and lifestyle, and this emerging business model and logic has also become a hotspot of extensive research in academia (Fumagalli et al., 2018; Kenney \& Zysman, 2020).

However, the entire platform economy is still in the early stages of development. The relationship between participants in the business ecosystem is relatively complex (Hoang, Blank, \& Quan-Haase, 2020), and the governance mechanism of platform companies is not yet complete. The operation of platform companies causes " "Data disputes between platforms", "platform corporate responsibility boundaries are difficult to determine" and "platform models challenge traditional antitrust restrictions" and other hot issues that have attracted social attention (Shelanski, 2013). The advancement of platform corporate governance research has become a point that needs urgent attention. In the research of platform corporates, governance is often mentioned. However, it is different from traditional enterprises in multiple subjectivity, strong harmfulness and governance complexity. Platform governance has not yet reached a unified conclusion. The governance mechanism is in the process of continuous development and improvement.

In view of this, this study sorts out and summarizes important articles of "Platform Governance" in recent years by entering the keywords "Platform Governance", "Digital Platform" and "Platform Economy" in the Web of Science database (Highly ranked in Science or more frequently cited). First, it expounds the connotation of platform governance, then clarifies the main perspectives and results of platform governance, explores the law and context of research development, and finally summarizes the prominent characteristics of platform corporate governance. This research hopes to follow up on the international frontiers of platform governance research through the research summary of previous literature, so that the scattered research results will be more systematic, and provide useful references for breakthroughs and innovations in future research and applications. At the same time, the platform corporates are allowed to operate within the boundaries of laws and systems, assume the social responsibilities of the main body of commercial operation, and coordinate and control the relationship between multiple subjects. 


\section{PLATFORM CORPORATE AND GOVERNANCE CONNOTATION}

\section{Platform and Platform Corporate}

The platform theory has been studied for a long time in the academic circle, but there is no unified understanding (Schwarz, 2017). Early research on the concept of platform focused on the field of industrial organization and strategic innovation. The field of industrial organization paid more attention to two-side market research (Rochet \& Tirole, 2003), and the field of strategic innovation paid more attention to product and innovation platform research. (Thomas, Autio, \& Gann, 2014). Armstrong (2006) believes that the platform is an agent of bilateral market interaction, characterized by cross-network effects, connecting groups in the bilateral market through the platform, and providing services to buyers and sellers of products or services through a certain price strategy, while groups join the platform to gain benefits. It depends on the size of the other side of the group to join the platform. Gillespie (2010) believes that a platform brings together different participants, and its connotation is related to platform developers, users, advertisers, etc., enabling interaction between multiple different subjects (Helmond, 2015). The key to the evolution of the business ecosystem from platform to platform lies in the symbiotic dependence of open platforms and multi-agents in the ecosystem. Gawer (2000) defines a platform from the perspective of a business ecosystem as a series of corporates composed of a business ecosystem as basic modules that can provide complementary products, technologies or services. At the same time, he also pointed out that the industrial platform must be distinguished from the product platform. The product platform is only a simple combination of building modules and does not involve innovation by other participants. On this basis, Cusumano (2010) pointed out that two important differences between the industrial platform and the product platform are: the industrial platform provides corporates with a common foundation that can be reused in different product types. Like the product platform, the industrial platform One function is a platform design system, and its constituent elements come from different companies that are usually called complementarity. Without these complementary products and services, the industry platform is of little value to users.

In this study, platform corporates refer to companies that are based on computer network technology and rely on Internet technology to survive, use network platforms to provide goods or services and thus obtain income, with typical bilateral market characteristics (Plantin et al., 2018; Kornberger et al., 2017), such as Facebook and Alphabet. The core difference between platform companies and traditional companies lies in the characteristics of connecting multilateral entities. The platform architecture includes demand-side users, supply-side users and platform providers, and there are same-side and cross-side network effects among users. In response to this definition, two types of research phenomena have been excluded. One is a platform for unilateral users or users with more than three times. The fully self-operated ecommerce platform belongs to unilateral users, such as the early JD model; for platforms involving trilateral users, its simplified to a bilateral situation. The second is traditional organizational forms such as commercial department stores and wholesale markets. The research focuses on a new platform based on the development of Internet information technology driven by the digital economy. The network effect of platform companies and the characteristics of bilateral markets will affect efficiency and social welfare changes. Scholars have analyzed the field of platform governance. 


\section{Governance and Platform Governance}

The term "governance" originated in the field of French government management in the Middle English era and means "guidance and rules." Corresponding to this origin, the research on governance theory also emerged in the field of political science, especially public administration (Fukuyama, 2013; Dawes, 2009). Based on a macro perspective, research on governance theory is mainly concentrated in the field of public management. According to Fukuyama, governance is "the ability of the government to formulate and implement rules and provide services" (Fukuyama, 2013), which is commonly used by political scientists as "good governance". It refers to the ability of a country to establish functions and effective institutions, and to use these institutions to maintain law and order (Weiss, 2000). And Stoker (1998) believes that governance is not only an ability but also a specific and complex interactive network across different actors. The governance from the micro perspective is mainly in the field of corporate governance, and the problem to be solved is mainly the agency risk caused by the separation of corporate ownership and management under the corporate system (Betle \& Means, 1932). Early corporate governance theories took shareholder interests as the ultimate goal (Jensen \& Meckling, 1976). Following the occurrence of a series of political and economic events (several financial crises and many corporate financial scandals) after the 1980s, more and more people are aware of the narrowness and short-sightedness of this view, and governance should also pay attention to the value of stakeholder groups. In addition to paying attention to agency problems and exploration problems within the company in corporate governance, traditional corporate governance research has also expanded from within the company to inter-company (Claussen et al., 2015). The goal is to resolve conflicts of interest between corporates through the balance and complementarity of contract governance and relationship governance, and jointly promote the performance improvement of cooperatives (Khanna \& Yafeh, 2007). Combining the research results of scholars, we can discover two core issues of governance. One is "multiple subjects", which coordinate the interest relationship between multiple subjects; the other is "system", which regulates the scope of behavior of each subject through the design of institutional rules.

Platform corporates, as a new business form in the digital economy (Tauscher\& Laudien, 2018), have changed their business model, economic form and organizational structure compared with traditional corporates. However, the governance process of platform corporates is still tightly centered on the two cores of "multi-agent" and "system" of corporate governance. Platform corporate governance does not simply refer to the internal governance process of a platform corporate, but lays more emphasis on the market governance of platform-based corporates. In addition to platform participants, platform corporate governance also includes the coordination of multiple main forces such as government, market and social organizations. At the same time, it is not limited to the authoritative, pluralistic and polycentric institutional arrangements in the general sense. In addition to some formal policy provisions and legal norms, informal moral and value constraints and controls should also be considered. In this way, the responsibilities of different subjects such as the government, corporates and users are clarified, and the platform is promoted to connect the subjects, so as to maintain the continuous interaction of forces among various subjects (Tiwana, 2010; Nieborg \& Poell, 2018). From this point of view, the governance of platform corporates involves the governance of the ecosystem connected to the platform, the content and boundary of governance are constantly changing, and the governance process is dynamic and complex. The following is a review of the research results of scholars from the perspective of governance bodies, governance systems and governance mechanisms. 


\section{MAIN VIEWPOINTS OF PLATFORM GOVERNANCE}

\section{Based on Governance Body}

The operation process of platform corporates connects multiple bodies, and it is difficult to solve various problems if the governance of platform corporates starts from the platform corporates themselves. In the current research, from the perspective of platform governance participants, from platform corporates themselves to multi-stakeholders, according to the different entities involved, scholars' views can be summarized as Centralization governance and Decentralization Governance (Chen Yan et al., 2020; Tiwana, 2014; Sutherland \& Jarrahi, 2018), but generally advocate the decentralization governance of multi-party power with platform companies as the core.

The participants of centralization governance are the owners of platform corporates. Platform owners make governance decisions based on market demand and corporate strategic goals, and take relatively decisive and independent actions to ensure the effectiveness of the governance process and structure. In his research, Gorwa (2019) put forward platform corporate autonomy, that is, "self-governance" or "self-regulation". Platform companies have a high degree of autonomous decision-making power and are directly responsible for third-party feedback or complaints, but they are not right. Users are responsible for matters negotiated through this platform. In this mode, the established laws and regulations only play a small role in the supervision of the governance of the platform. The platform mainly improves the transparency and fairness of the subject's interaction process through the improvement of its own technology or rules (Suzor, 2018). Data drives the decision-making of platform companies. The algorithm and iteration of data in the process itself is a "black box". Platform corporate autonomy helps protect the company's business secrets and promote the innovation and development of the company. Projects can be quickly and effectively implemented, and the work process and production The export standard is more flexible (Brown \& Grant, 2005). However, centralization governance, because the governance decision-making power is mainly concentrated on the platform owner, lacks sufficient checks and balances, resulting in the platform owner may act for the maximization of their own interests (Mookherjee, 2006) and damage the rights of other stakeholders. Also, the lack of direct communication in the interactive process of the bilateral market connected by the platform affects the efficiency of transactions.

Decentralization governance fully considers the characteristics of platform companies connecting multilateral markets and multi-party entities, and leading platform corporate governance needs to consider more participants. One view is to rely on government forces for external governance. This claim is based on the consideration of user safety and privacy protection (such as platform companies leaking users' personal information accessed through APP, frequent online car-hailing damage to passengers, property and personal safety incidents). In practice, the governance of platform corporates is mainly through the government's policy intervention in three aspects, namely, privacy and data protection regulations, abolition of intermediate liability protection, and the use of competition law and monopoly law. On the one hand, platform companies are allowed to operate in a standardized network data space, and on the other hand, legal measures are adopted to protect the rights and interests of platform users. Because of the ambiguity of the boundaries of platform companies and the complexity of network relationships, policies are usually only further defined after the incident, so it is still difficult to achieve in the short term. However, legislation on user data and privacy, as well as antitrust laws and anti-competitive behaviors on platforms have attracted social attention 
(Tisne, 2018; Pasquale, 2018). Another view is the combination of platform autonomy and external governance, that is, taking into account the cooperative governance or co-governance of platform owners, participants and external stakeholders. Through the decentralization of governance power, the hierarchy of power in the organization is eliminated, the decisionmaking power is allocated to multiple parties, and the multiple parties jointly negotiate the performance realization and value distribution of the platform. Under the governance power, it can enhance the power of platform participants, limit the behavior of platform owners (Cheibub, Gandhi, \& Vreeland, 2010), eliminate decision-making bottlenecks, make the complex governance process clear, and the power of government and social organizations makes that the platform Corporate governance is regulated under the framework of law and ethics. The participation of platform users can transform decentralized network governance into the self-management of the platform community, and provide users with a fairer and just digital economy (Scholz, 2016; Scholz \& Schneider, 2017). Community governance has strong coordination, which can help adjust the overall incentive mechanism, coordinate actions, reduce conflicts, and sort out common identities (Di Tullio, \& Staples, 2013). Under collaborative governance, different responsibilities are assigned to the stakeholders (platforms, users, and governments) of platform companies, and certain governance powers are given to enable these actors to effectively assume responsibilities, develop the concept of collaborative responsibility, and standardize the platform, Cooperative governance of users and government in public space (Helberger, Pierson, \& Poell, 2018). With the joint efforts of multiple parties, the responsibility of the platform company itself is mainly to assume the social responsibility of data protection, and to create good platform conditions to enable individual users to comply with their responsibilities.

In general, there are great differences between decentralization governance and centralization governance in the distribution of participants and decision-making power. Gol (2019) studies crowdsourcing platforms in digital platforms, discusses the relationship between platform governance mechanism and value creation, and compares the differences between centralized and decentralization governance in detail from aspects of workflow, communication, decision making, standards, cost control, quality control and performance control. Decentralization governance is characterized by overlapping workflow, direct communication between participants, transparent decision-making process, flexible adjustment based on standards and high cost control.

\section{Based on Governance System}

The participation of multiple bodies in the governance of platform corporates should be based on a certain system, which makes the governance procedures more standardized and comprehensive, and the rights and responsibilities between various subjects clearer. On the one hand, the establishment of reward and punishment system can restrict the decision-making of platform owners, and on the other hand, it can also encourage multi-parties to realize selfregulation in the value co-creation system constructed by participating platform corporates. From the perspective of governance system, it can be mainly divided into the governance based on formal system and the governance based on informal system, which imposes restrictions on the interaction between platform owners and stakeholders (Constantinides, Henfridsson, \& Parker, 2018). To ensure that the best interests of platform developers are aligned with those of platform owners, while preventing direct interactions between producers and consumers outside the platform from harming the platform's economic interests (Rochet\& Tirole, 2003; Rochet\& Tirole, 2006). The formal system mainly refers to legislation, discipline, supervision 
and punishment, etc., while the informal system includes various codes of conduct, corporate culture, values and moral constraints of the platform corporates.

Facebook has used an eclectic mix of algorithmic and judicial governance tools to govern its vast social network. Algorithmic analysis of captured user data is used as a governance tool to generate different rules and monitor user behavior. Meanwhile, the legal system remains at the heart of Facebook's legal governance. Algorithmic governance is mainly used to organize the possible illegal information released by users in a timely manner, which is forward-looking to some extent. Judicial governance is the punishment of various illegal and criminal problems, and more of a guarantee after the event (Schwarz, 2019). Another example is the Apple App Store, where regulators will legislate to restrict Apple's access to users' personal data, and at the same time, Apple itself encourages the development of technologies that cannot access users' data as a new design specification for the platform ecosystem (Simonite, 2016). Google also encourages the innovation of user privacy protection functions, but not in the form of legislation, but from the perspective of social morality, the innovation of self-developed technology is used as a governance tool (Greene\& Shilton, 2018). In the digital economy, consumer privacy violations caused by apps are common, and there is no choice but to trust an app completely or refuse to use it. For this problem, the platform's development technology promotion is the fundamental governance.

The strategic design and deployment of platform governance policies can be an important tool for platform governance. Owners of innovation platforms develop layered platform access policies to dynamically adjust the cooperation and interaction between complementaries in platform submarkets and promote knowledge sharing through platform governance (Zhang et al., 2020). The "Platform Logic" proposed by Schwarz (2017) studies the concepts and mechanisms of digital platforms at the micro, meso and macro levels to structurally manage emergencies of various types of platforms (Kapoor \& Akarwal, 2017). The micro level refers to the interaction of individuals on the digital platform, the macro level mainly refers to the cumulative effect of various platform interactions seen from the social level, and the meso level focuses on the connection between the platform and the surrounding system. Therefore, for different levels of governance, the basis of the system measures is also different. At the micro level, the design of the platform's user interface is mainly improved, which mainly depends on the rules of the platform itself. The middle level is the management of big data and media, which is the more complex part of the current platform governance. At the macro level, political economy is involved, and platform governance is restricted by national laws and policies.

\section{Based on Governance Mechanism}

The main body of governance determines who governs, the dominant basis of governance system governs, and the governance mechanism answers the question of how to conduct governance. A key goal of the platform governance mechanism is to provide incentives to align the interests of stakeholders (Kapoor\& Agarwal, 2017; Song et al., 2018), so the allocation of power in governance is crucial. In the existing researches, platform governance mechanism mainly focuses on power grant and process guarantee. Delegation includes the establishment of intellectual property rights (Eisenman,2008), the decentralization of decision-making rights (Tiwana et al.,2010) and the placement of control points (Dattee, Alexy, \& Autio, 2008); Process assurance mainly consists of adjusting incentives for buyers and sellers of the platform (Song et al.,2018), adjusting incentives for complementaries (Wareham, Fox, \& Giner,2014), public communication governance costs (Huber, Kude, \& Dibbern, 2017) and detecting outputs (Wareham, Fox, \& Giner,2014). 
Tiwana (2010) points out that the design of platform governance mechanism can be studied from three different perspectives, namely, decision right division, control and governance attributes. Decision-making power is embodied in who has the right and responsibility to make what kind of decisions to platform corporates. The decentralization of governance power makes the balance of decision-making power among various subjects become the key to the coordination of platform ecosystem relations. The decision rights at three levels should be distinguished, namely, what features and functions the platform has, how to design the user interface, and who controls the internal interface of the ecosystem. Control mainly refers to a variety of rewards and punishments set by platform owners to motivate developers, including output control and process control. In addition, the interaction between stakeholders of the platform and the differences of interests between them should also be controlled. Governance attributes mainly refer to whether the platform is owned by a single corporate or shared by multiple owners. In this process, you need to achieve transparency, diversity and responsibilities assigned to the platform of public value such as the corporate's stakeholders, each stakeholder role in realizing the value, and to agree on how to improve the public value, the consultation results into a code of conduct (Helberger, Pierson, \& Poell,, 2018). Schreieck et al. (2017) discussed the platform governance mechanism from four aspects: governance structure, platform access and control, trust building and boundary resources. The governance structure can be centralized or relatively decentralized, which is mainly the division of governance decision-making power and platform ownership. The openness of the platform ecosystem determines that the governance process needs more control; The establishment of trust mechanism is crucial for participants to reduce risk perception and continue interaction (Pavlou, 2002). Intangible and effective boundary resources play a certain role in the implementation of platform governance strategy (Ghazawneh \& Henfridsson, 2013).

Airbnb is a model of platform corporates. Leoni studied and analyzed its governance and control system, including the division of decision-making rights between Airbnb and participants and how the platform owner formally controls the participants (Leoni\& Parker, 2019). The platform maintains autonomy in decision making in four major areas, listing, pricing, booking process, and accommodation rules, in order to maintain the performance of the platform and the interests of the platform owner. The behavior of the platform participants is monitored by the platform, such as the ratings provided by the tenants, the response rate of the platform algorithm, and so on. Through power division and a series of control technologies, the performance goals of platform users and platform organizations can be consistent, thus leading to more organizational citizenship behaviors. The governance of platform corporates will be in a relatively loose state, which will help promote the order and innovation of the platform ecosystem.

\section{CHARACTERISTICS OF PLATFORM CORPORATE GOVERNANCE IN DIGITAL ECONOMY}

Through studying the achievements of the academic community on the governance of platform corporates, it is found that under the background of the digital economy, the governance of platform corporates has attracted attention from all walks of life. It is no longer the same as the traditional corporate governance, aiming at the interest disputes within the corporate, which is gradually implemented by the senior management to the employees. Platform corporate governance not only expands the responsibility of being an independent operator, but also embodies the responsibility of being a commercial operation platform and the responsibility of resource allocation and integration in the social system (Acquier, Daudigeos, \& Pinkse,2017; 
Schor, 2017). The governance of platform corporates presents the characteristics of multiple subjectivity, open boundary, dynamic relationship and fuzzy rights and responsibilities.

\section{Multiple Subjectivity}

Besides platform owners, platform participants and social forces are also the main body of governance of platform corporates. Platform participants, in terms of the services provided by the platform, include complementaries in bilateral markets, developers of the platform corporate, and other participants in the value creation process of the platform ecosystem (Courtois\& Timmermans, 2018). Social forces are organizations outside the platform ecosystem, involving governments, communities, and other regulatory agencies (Berkowitz \& Souchaud, 2019). Multiple subjects play an unreasonable role in the process of participating in platform governance (Ansell \& Miura, 2019). In general, platform owners and platform developers are mainly responsible for the improvement of platform technology and functions to ensure the efficient, transparent and orderly two-way market interaction process. Platform participants participate in the governance process to facilitate the normative operation of datadriven platform business and focus on the creation of social value (Alreshidi, Mourshed, \& Rezgui,2016; Saadatmand, Lindgren, \& Schultze,2019); The government and regulatory agencies play a controlling role in the governance process to ensure that this emerging business logic has a real significance to promote China's innovation-driven strategic transformation. Collaborative governance of embedded platform connecting plural ecosystem (Ansell \& Gash, 2018), a complex network intertwined relationships, the value creation process by multiple subject and elements of ecological system is complete, each subject in the common governance holding power and responsibility and platform of business ecosystem symbiosis (BasoLe \& Karla, 2011).

\section{Boundary Openness}

One of the characteristics of platform corporates is the uncertainty of the boundary, and the boundary of platform governance is also open. Scholars have explained in their studies that the governance of platform corporates can start from the micro, meso and macro levels. The micro level focuses on the platform itself, the meso level focuses on the relationship between the platform and the main body of the ecosystem, and the macro level focuses on the platform ecosystem (Schwarz, 2017). But in the actual governance process, the three levels are blended with each other, and each level also involves more contents. Platform corporate itself as the main body of independent operation, as well as other corporates (Culpepper \& Thelen, 2020). The core of platform corporates lies in the interaction between the two sides of the market, and the behavior of the supply side and the user side also needs to meet the requirements of governance responsibility. For example, the development of shared bikes has made people's travel more convenient and green, but it has led to the undesirable phenomenon of random parking, malicious destruction and possession. The platform ecosystem enables the valuecreation process to mobilize and allocate more social resources, and accordingly, the governance process needs to highlight the paradigm of social responsibility fulfillment. On the basis of legal operation, it should also save factor resources, improve the efficiency of resource allocation, promote the sharing of knowledge, protect innovation patents, take the initiative to assume social responsibilities, jointly participate in solving social problems, and promote the strategic transformation and sustainable development of social economy (Kenney\& Zysman, 2016; Martin, Upham,\& Klapper, 2017; Geissinger et al.,2019). 


\section{Dynamic Relationship}

A major difficulty in platform corporate governance lies in the dynamic relationship of platform system, which makes the original layer nested network relationship more complex (Schmeiss, Hoelzle, \& Tech, 2019). On the one hand, in the era of digital economy, big data analysis and artificial intelligence are the keys to drive the decision-making of platform corporates. The algorithm of platform corporates is fast, so the business model is constantly adjusted and innovated (Gong et al., 2020). On the other hand, the transactions reached by platform participants are changing in real time. Moreover, the competition between different platforms is increasingly intensified, and the relationship between the platform and the subject is also changing rapidly. There is no traditional employment contract relationship. Because it involves the allocation of social resources, there is also a relationship between platform corporates and social systems (Gerwe\& Silva, 2020). Therefore, platform corporate governance involves the dynamic adaptability of the relationship between "individual and individual", "individual and platform" and "platform corporate and society". For example, the driving distance and fuel consumption of online hailing cars without load should be as little as possible, and the carrying distance and times of shared bikes between different stations should also be as little as possible. The optimization of the platform ecosystem not only shortens the value creation cycle and reduces the cost of the platform, but also reduces the consumption of social resources and improves the efficiency. However, the solution of the problems in the dynamic environment also needs to have the vision of development, taking into account the interest disputes and responsibility conflicts in the governance process.

\section{Ambiguity of Rights and Responsibilities}

Whether it is platform self-governance or multi-party cooperative governance, there are problems of power division and responsibility assumption in the process of platform corporate governance. Although, the governance mechanism of platform corporates all mentioned the two aspects of decision-making and control (Martin, Upham, \& Klapper, 2017), and proposed how to allocate decision-making rights among multiple subjects, as well as how to ensure the implementation of various projects and rules. However, in the practice of platform corporate governance, it is still difficult to clarify the responsibility of each subject. At present, it is mainly centralization governance. The decision-making power of governance is mainly concentrated in the platform owner, and the control of the governance process is realized by the government's policies and regulations. The participation of platform participants and other stakeholders in governance is low. Platform rely on policies and laws of ecological system and the formalized method can only play a role in mandatory norms (Suzor, 2018; Lehdonvirta, 2018).

\section{CONCLUSION}

The development of the digital economy has enabled the operation of platform corporates. The innovative business model of platform corporates has brought great changes to the value creation methods of traditional corporates, but at the same time, it has also triggered a variety of common social problems. The governance of platform corporates has become a hot topic of academic research in recent years. This study sorts out and summarizes the viewpoints and conclusions of scholars on platform governance. Firstly, the connotation of platform corporate and platform governance is discussed. Then from the three aspects of governance body, governance system and governance mechanism, illustrates the main ways and means of platform for corporate governance. Mobilize various main collaborative governance of power, 
the combination of formal system and informal system balance management, decentralized decision-making power and more ways to control the loose coupling of cooperative governance, is the current mainstream view. In the final analysis to summarize the characteristics of the platform for corporate governance, the subject pluralism, openness, border relationship dynamics and accrual fuzziness, we point out the platform stakeholder participation in the corporate governance practices, responsibility, multi-level, dynamic network and informal system USES fewer problems, platform business management practice that provides guidance for the future.

\section{REFERENCES}

Acquier, A., Daudigeos, T., Pinkse, J. (2017). Promises and paradoxes of the sharing economy: An organizing framework. Technological Forecasting and Social Change, 125, 1-10. DOI: 10.1016/j.techfore.2017.07.006

Adamik, A., Nowicki, M. (2018). Preparedness of companies for digital transformation and creating a competitive advantage in the age of Industry 4.0. Proceedings of The International Conference on Business Excellence, 12(1), 10-24. DOI: 10.2478/picbe2018-0003

Akbar, YH., Tracogna, A. (2018). The sharing economy and the future of the hotel industry: transaction cost theory and platform economics. International Journal of Hospitality Management, 71, 91-101. DOI: 10.1016/j.ijhm.2017.12.004

Alreshidi, E., Mourshed, M., Rezgui, Y. (2016). Cloud-based BIM governance platform requirements and specifications: Software engineering approach using BPMN and UML. Journal of Computing In Civil Engineering, 30(4). DOI: 10.1061/(ASCE)CP.19435487.0000539

Ansell, C., Gash, A. (2018). Collaborative platforms as a governance strategy. Journal of Public Administration Research and Theory, 28(1), 16-32. DOI: 10.1093/jopart/mux030

Ansell, C., Miura, S. (2019). Can the power of platforms be harnessed for governance? Public Administration, 98(1), 261-276. DOI: 10.1111/padm.12636

Armstrong, M. (2006). Competition In Two - Sided Markets. The RAND Journal of Economics, 37 (3), 668-691. DOI: 10.1111/j.1756-2171.2006.tb00037.x

Ayres, RU., Williams, E. (2004). The digital economy: Where do we stand?. Technological Forecasting and Social Change, 71(4), 315-339. DOI: 10.1016/j.techfore.2003.11.001

Basole, RC., Karla, J. (2011). On the evolution of mobile platform ecosystem structure and strategy. Business \& Information Systems Engineering, 3(3), 313-322. DOI: 10.1007/s12599-011-0174-4

Benlian, A., Hilkert, D., Hess, T. (2015). How open is this platform? The meaning and measurement of platform openness from the complementors' perspective. Journal of Information Technology, 30(3), 209-228. DOI: 10.1057/jit.2015.6

Berkowitz, H., Souchaud, A. (2019). (Self-)regulation of sharing economy platforms through partial meta-organizing. Journal of Business Ethics, 159(4), 961-976. DOI: 10.1007/s10551-019-04206-8

Brown, A. E., Grant, G. G., (2005). Framing the frameworks: a review of it governance research. Communications of the Association for Information System, 15 (1), 38. DOI: 10.17705/1CAIS.01538

Cheibub, J. A., Gandhi, J., Vreeland, J. R. (2010). Democracy and dictatorship revisited. Public Choice, 143, 67-101. DOI: 10.1007/s11127-009-9491-2

Chen, Yan., Pereira, Igor; Patel, Pankaj, C. (2020). Decentralized governance of digital platforms. Journal of Management. DOI: 10.1177/0149206320916755 
Claussen, J., Essling, C., Kretschmer, T. (2015). When less can be more-setting technology levels in complementary goods markets. Research Policy, 44(2), 328-339. DOI: 10.1016/j.respol.2014.10.005

Constantinides, P., Henfridsson, O., Parker, G. G. (2018). Platforms and infrastructures in the digital age. Information Systems Research, 29(2), 381-400. DOI: 10.1287/isre.2018.0794

Courtois, C., Timmermans, E. (2018). Cracking the tinder code: an experience sampling approach to the dynamics and impact of platform governing algorithms. Journal of Computer-Mediated Communication, 23(1), 1-16. DOI: 10.1093/jcmc/zmx001

Culpepper, PD., Thelen, K. (2020). Are we all amazon primed? Consumers and the politics of platform power. Comparative Political Studies, 53(2), 288-318. DOI: $10.1177 / 0010414019852687$

Cusumano, M. (2010). The evolution of platform thinking, Communications of The Acm, 53(1), 32-34. DOI: $10.1145 / 1629175.1629189$

Dattee, B., Alexy, O., Autio, E., (2018). Maneuvering in poor visibility: how firms play the ecosystem game when uncertainty is high. Academy of Management Journal, 61 (2), 466-498. DOI: 10.5465/amj.2015.0869

Dawes, S. S. (2009). Governance in the digital age: a research and action framework for an uncertain future. Government Information Quarterly, 26(2), 257-264. DOI: 10.1016/j.giq.2008.12.003

de Reuver, M., Sorensen, C., Basole, R. C. (2018). The digital platform: a research agenda. Journal of Information Technology, 33(2), 124-135. DOI: 10.1057/s41265016-0033-3

Di Tullio, D., Staples, D. S. (2013). The governance and control of open source software projects. Journal of Management Information Systems, 30(3), 49-80. DOI: 10.2753/MIS0742-1222300303

Eisenmann, TR., (2008). Managing proprietary and shared platforms. California Management Review, 50 (4), 31-53. DOI: 10.2307/41166455

Fukuyama, F. (2013). What is governance? Governance-An International Journal of Policy Administration and Institutions, 26(3), 347-368. DOI: 10.1111/gove.12035

Fumagalli, A., Lucarelli, S., Musolino, E.\& Rocchi, G. (2018). Digital labour in the platform economy: the case of Facebook. Sustainability, 18(6). DOI: 10.3390/su10061757

Kahl, S. (2011). Platforms, markets and innovation. Organization Studies, 32(4), 571-573. DOI: $10.1177 / 0170840611400273$

Gawer, A., Cusumano, MA. (2014). Industry platforms and ecosystem innovation, Journal of Product Innovation Management, 31(3), 417-422. DOI: 10.1111/jpim.12105

Gawer. (2014). Bridging differing perspectives on technological platforms: toward an integrative framework. Research Policy, 3(7), 1239-1249. DOI: 10.1016/j.respol.2014.03.006

Geissinger, A., Laurell, C., Oberg, C., Sandstrom, C. (2019). How sustainable is the sharing economy? On the sustainability connotations of sharing economy platforms. Journal of Cleaner Production, 206, 419-429. DOI: 10.1016/j.jclepro.2018.09.196

Gerwe, O., Silva, R. (2020). Clarifying the sharing economy: conceptualization, typology, antecedents, and effects. Academy of Management Perspectives, 34(1), 65-96. DOI: 10.5465/amp.2017.0010

Ghazawneh, A., Henfridsson, O. (2013). Balancing platform control and external contribution in third-party development: the boundary resources model. Information Systems Journal, 23(2), 173-192. DOI: 10.1111/j.1365-2575.2012.00406.x

Gillespie, T. (2010). The politics of "Platforms." New Media \& Society, 12, 347-364. Doi: $10.1177 / 1461444809342738$ 
Gol, E. S., Stein, M., Avital, M. (2019). Crowdwork platform governance toward organizational value creation. Journal of Strategic Information Systems, 28(2), 175-195. DOI: $10.1016 /$ j.jsis.2019.01.001

Gong, DQ., Liu, SF., Liu, J., Ren, L. (2020). Who benefits from online financing? A sharing economy e-tailing platform perspective. International Journal of Production Economics, 222. DOI: $10.1016 /$ j.ijpe.2019.09.011

Gorwa, R. (2019). What is platform governance? Information Communication \& Society, 22(6), 854-871. DOI: 10.1080/1369118X.2019.1573914

Greene, D., Shilton, K. (2018). Platform privacies: governance, collaboration, and the different meanings of "Privacy" in iOS and android development. New Media \& Society, 20(4), 1640-1657. DOI: $10.1177 / 1461444817702397$

Hanseth, O., Lyytinen, K. (2010). Design theory for dynamic complexity in information infrastructures: the case of building internet. Journal of Information Technology, 25(1), 1-19. DOI: $10.1057 /$ jit.2009.19

Helberger, N., Pierson, J., Poell, T. (2018). Governing online platforms: from contested to cooperative responsibility. Information Society, 34(1), 1-14. DOI: 10.1080/01972243.2017.1391913

Helmond, A. (2015). The platformization of the web: making web data platform ready. Social Media + Society, 1(2). DOI: 10.1177/2056305115603080

Hoang, L., Blank, G., Quan-Haase, A. (2020). The winners and the losers of the platform economy: Who participates? Information Communication \& Society, 23(5), 681-700. DOI: $10.1080 / 1369118 X .2020 .1720771$

Huber, T.L., Kude, T., Dibbern, J. (2017). Governance practices in platform ecosystems: navigating tensions between co-created value and governance costs. Information Systems Research. 28(3), 563-584. DOI: 10.1287/isre.2017.0701

Jensen, M. C., Meckling, W. H. (1976). Theory of the firm: managerial behavior, agency costs and ownership structure. Journal of Financial Economics, 3(4), 305-360. DOI: 10.1016/0304-405X(76)90026-X

Kannan, PK., Kopalle, PK. (2001). Dynamic pricing on the internet: importance and implications for consumer behavior. International Journal of Electronic Commerce, 5(3), 63-83. DOI: 10.1080/10864415.2001.11044211

Kapoor, R., Agarwal, S., (2017). Sustaining superior performance in business ecosystems: evidence from application software developers in the IOS and Android smartphone ecosystems. Organization Science, 28 (3), 531-551. DOI: 10.1287/orsc.2017.1122

Kenney, M., Zysman, J. (2016). The rise of the platform economy. Issues in Science and Technology, 32(3), 61-69.

Kenney, M., Zysman, J. (2020). The platform economy: restructuring the space of capitalist accumulation. Cambridge Journal of Regions Economy and Society, 13(1), 55-76. DOI: 10.1093/cjres/rsaa001

Khanna, T., Yafeh, Y. (2007). Business groups in emerging markets: paragons or parasites?. Journal of Economic Literature, 2007: 331-372. DOI: 10.1257/jel.45.2.331

Kim, B., Barua, A., Whinston, AB. (2002). Virtual field experiments for a digital economy: a new research methodology for exploring an information economy. Decision Support Systems, 32(3), 215-231. DOI: 10.1016/S0167-9236(01)00094-X

Kornberger, M., Pflueger, D., Mouritsen, J. (2017). Evaluative infrastructures: accounting for platform organization. Accounting, Organizations and Society, 60, 79-95. DOI: 10.1016/j.aos.2017.05.002

Kovacs, O., (2018). The dark corners of industry 4.0-grounding economic governance 2.0. Technology in Society, 55, 140-145. DOI: 10.1016/j.techsoc.2018.07.009 
Lee, K., Malerba, F., Primi, A. (2020). The fourth industrial revolution, changing global value chains and industrial upgrading in emerging economies. Journal of Economic Policy Reform, 23(4), 359-370. DOI: 10.1080/17487870.2020.1735386

Lehdonvirta, V., Kassi, O., Hjorth, I., Barnard, H., Graham, M. (2019). The global platform economy: a new offshoring institution enabling. Emerging-economy microproviders. Journal of Management ,45(2), 567-599. DOI: 10.1177/0149206318786781

Lehdonvirta, V., (2018.). Flexibility in the gig economy: managing time on three online piecework platforms. New Technology Work and Employment, 33(1), 13-29. DOI: $10.1111 /$ ntwe. 12102

Leoni, G., Parker, L D. (2019). Governance and control of sharing economy platforms: Hosting on Airbnb. British Accounting Review, 51(6). DOI: 10.1016/j.bar.2018.12.001

Liang Zheng., Li Rui. (2020). New techno-economic paradigm and global competition pattern in digital age. Science \& Technology Review, 38(14), 142-147.

Makridakis, S. (2017). The forthcoming artificial intelligence (AI) revolution: its impact on society and firms. Futures, 90, 46-60. DOI: 10.1016/j.futures.2017.03.006

Martin, CJ., Upham, P., Klapper, R. (2017). Democratising platform governance in the sharing economy: an analytical framework and initial empirical insights. Journal of Cleaner Production,166, 1395-1406. DOI: 10.1016/j.jclepro.2017.08.123

Mookherjee, D. (2006). Decentralization, hierarchies, and incentives: a mechanism design perspective. Journal of Economic Literature, 44, 367-390. DOI: 10.1257/jel.44.2.367

Nieborg, D. B., Poell, T. (2018). The platformization of cultural production: theorizing the contingent cultural commodity. New Media \& Society. Doi:10.1177/1461444818769694

Pasquale, F. (2018). Tech platforms and the knowledge problem. American Affairs, 2(2).

Pavlou, PA. (2002). Institution-based trust in interorganizational exchange relationships: the role of online B2B marketplaces on trust formation. Journal of Strategic Information Systems, 11(3-4), 215-243. DOI: 10.1016/S0963-8687(02)00017-3

Plantin, J., Lagoze, C., Edwards, P. N., Sandvig, C. (2018). Infrastructure studies meet platform studies in the age of Google and Facebook. New Media \& Society, 20(1), 293-310. DOI: $10.1177 / 1461444816661553$

Rochet, J. C., Tirole, J. (2003). Platform competition in two - sided markets. Journal of The European Economic Association, 1(4), 990-1029. DOI: 10.1162/154247603322493212

Rochet, J. C., Tirole, J. (2006). Two-sided markets: a progress report. RAND Journal of The European Economic Association, 37(3), 645-667. DOI: 10.1111/j.17562171.2006.tb00036.x

Saadatmand, F., Lindgren, R., Schultze, U. (2019). Configurations of platform organizations: implications for complementor engagement. Research Policy, 48(8). DOI: 10.1016/j.respol.2019.03.015

Sambamurthy, V., Bharadwaj, A., Grover, V. (2003). Shaping agility through digital options: reconceptualizing the role of information technology in contemporary firms. MIS Quarterly, 27(2), 237-263.

Schmeiss, J., Hoelzle, K., Tech, RPG. (2019). Designing governance mechanisms in platform ecosystems: addressing the paradox of openness through blockchain technology. California Management Review, 62(1), 121-143. DOI: 10.1177/0008125619883618

Scholz, T. (2016). Platform cooperativism (challenging the corporate sharing economy). New York: Rosa Luxemburg Foundation.

Scholz, T., Schneider, N. (2017). Ours To Hack And To Own: The Rise Of Platform Cooperativism, A New Vision For The Future Of Work And A Fairer Internet. New York, NY: OR Books. 
Schor, JB. (2017). Does the sharing economy increase inequality within the eighty percent?: Findings from a qualitative study of platform providers. Cambridge Journal of Regions Economy and Society, 10(2), 263-279. DOI: 10.1093/cjres/rsw047

Schreieck, M., Wiesche, M., Krcmar, H. (2017). Governing nonprofit platform ecosystems an information platform for refugees. Information Technology for Development, 23(3), 618-643. DOI: 10.1080/02681102.2017.1335280

Schwarz, J. A. (2017). Platform logic: an interdisciplinary approach to the platform-based economy. Policy \& Internet, 9(4), 374-394. DOI: 10.1002/poi3.159

Schwarz, O. (2019). Facebook rules: structures of governance in digital capitalism and the control of generalized social capital. Theory Culture \& Society, 36(4), 117-141. DOI: $10.1177 / 0263276419826249$

Shelanski, H. A. (2013). Information, innovation, and competition policy for the Internet. University of Pennsylvania Law Review, 161(6), 1663-1705.

Simonite, T. (2016). Apple's New Privacy Technology May Pressure Competitors To Better Protect Our Data. MIT Technology Review.

Song, P., Xue, L., Rai, A., Zhang, C., (2018). The ecosystem of software platform: a study of asymmetric cross-side network effects and platform governance. MIS Quarterly, 42 (1),121-142. DOI: $10.25300 / \mathrm{MISQ} / 2018 / 13737$

Stoker, G. (1998). Governance as theory: five propositions. International Social Science Journal, 50(155), 17-28.

Sui, DZ., Rejeski, DW. (2002). Environmental impacts of the emerging digital economy: the e-for-environment e-commerce? Environmental Management, 29(2), 155-163. DOI: $10.1007 / \mathrm{s} 00267-001-0027-\mathrm{X}$

Sutherland, W., Jarrahi, M. H. (2018). The sharing economy and digital platforms: a review and research agenda. International Journal of Information Management, 43, 328-341. DOI: 10.1016/j.ijinfomgt.2018.07.004

Suzor, N., Van Geelen, T., Myers West, S. (2018). Evaluating the legitimacy of platform governance: a review of research and a shared research agenda. International Communication Gazette, 80(4):385-400. DOI: 10.1177/1748048518757142

Suzor, N. (2018). Digital constitutionalism: using the rule of law to evaluate the legitimacy of governance by platforms. Social Media + Society, 4(3). DOI: $10.1177 / 2056305118787812$

Tauscher, K., Laudien, SM. (2018). Understanding platform business models: a mixed methods study of marketplaces. European Management Journal, 36(3), 319-329. DOI: 10.1016/j.emj.2017.06.005

Thomas, L., Autio, E., Gann, D. (2014). Architectural leverage: putting platforms in context, The Academy of Management Perspectives, 28 (2), 198-219. DOI: 10.5465/amp.2011.0105

Tisne, M. (2018). It's Time For A Bill Of Data Rights. MIT Technology Review.

Tiwana, A. (2015). Evolutionary Competition in Platform Ecosystems. Information Systems Research, 26(2), 266-281. DOI: 10.1287/isre.2015.0573

Tiwana, A., Konsynski, B., Bush, A. A. (2010). Platform evolution: coevolution of platform architecture, governance, and environmental dynamics. Information Systems Research, 21(4), 675-687. DOI: 10.1287/isre.1100.0323

Wareham, J., Fox, PB., Giner, JLC. (2014). Technology ecosystem governance. Organization Science, 25 (4), 1195-1215. DOI: 10.1287/orsc.2014.0895

Weiss, T. G. (2000). Governance, good governance and global governance: conceptual and actual challenges. Third World Quarterly, 21(5), 795-814. 
Yoo, Y., Henfridsson, O., Lyytinen, K. (2010). The new organizing logic of digital innovation: an agenda for information systems research. Information Systems Research, 21(4), 724735. DOI: $10.1287 /$ isre. 1100.0322

Zhang, Yuchen., Li, Jingjing., Tong, Tony W. (2020). Platform governance matters: how platform gatekeeping affects knowledge sharing among complementors. Strategic Management Journal. DOI: 10.1002/smj.3191 